\title{
Evaluating Influential Factors in Event Quality Using DEMATEL Method
}

\author{
Wen-Tsann Yang, Wen-Hua Liu, Hsin-Hsien Liu, and Lanasari
}

\begin{abstract}
This research determines the influence of various dimensions and criteria of event quality. In addressing the aim of this study, a decision-making trial and evaluation laboratory (DEMATEL) is employed to construct an influential network relationship map (INRM), which then is used to illustrate the influential network of the event quality improvement model. The results indicated that entertainment dimension apparently is recognized as the main key which has most influence on other dimensions (information, transportation and environment). This improvement model is useful in establishing an influential network and a prioritization among dimensions/criteria associated with event quality in tourism industry.
\end{abstract}

Index Terms-Event, quality, dematel (Decision-Making Trial and Evaluation Laboratory).

\section{INTRODUCTION}

In recent decades, events have developed significantly in terms of number and size and have become such important phenomena in tourism industry. Events have offered enormous advantages to tourism industry, rapidly attracted many visitors, facilitated recreational, social and cultural experiences, increased media coverage and especially had great impact on local economic [1]-[6]. Events have stimulated economic activities, particularly increased business turnover, created employment field and enhanced local community income, as well as government revenue. In other words, events are major business including huge amounts of marketing that make many type of businesses depend on them for their success [7]. In this context, this success is derived from both direct and indirect large amount of time and money spent by visitors to attend those events.

For events success are greatly affected by visitors attendance and expenditures, one of challenges that event provider need to thrive on is to design an unforgettable experiences for visitors that will create loyal visitors base. In pursuit of this stage, provider has to consistently provide a good event quality first. For result, it will deliver outstanding experience for visitors that will lead to satisfaction, revisit intention and word-of-mouth. However, good event quality is determined by many factors. Specifically, provider should perceive and examine which factors that have most impact on delivering a better event quality.

Manuscript received April 13, 2013; revised June 14, 2013.

Wen-Tsann Yang, Wen-Hua Liu, and Hsin-Hsien Liu are with Ph. D Program in Civil and Hydraulic Engineering, Feng Chia University, Taichung, Taiwan (e-mail: wtyang@fcu.edu.tw; simon3579@hotmail.com; sunydidi@yahoo.com.tw).

Lanasari is with Suci Hati School, Jakarta, Indonesia. (e-mail: tan.ch.ling@gmail.com).
However, when decision makers of event make decisions from multiple factors, they must carefully deliberate many aspects, such as dependency and conflicts among the items. Further, each criterion has particular influence both within dimensions and overall quality. Consequently, decision making process becomes notably sophisticated [8], [9]. How to construct an evaluation system of improvement priorities is exceptionally demanding. This research applies DEMATEL (Decision-Making Trial and Evaluation Laboratory) method to discover the influential degree among factors and to facilitate provider with improvement solutions based on those priorities.

\section{LITERATURE REVIEW}

Event quality means product and service that delivered to satisfy visitors' needs at the appropriate level. For quality intuitively is a measure of event success in tourism and leisure services [10], [11], hence, event providers have to set affordable quality standards to meet visitors' needs.

Howard and Crompton [12] that applied Herzberg, Mausner, and Snyderman [13] concept of leisure study, recognized that fundamental key in visitors' satisfaction is affected by the tangible physical environment (superstructure and infrastructure) which is required for service performance in an event [14], [15]. These tangible environmental cues are recognized as an impulse that sway visitors' emotions for what they have experienced, then for the outcome, it will define their next behavior [16]. Further research by Brown [17] and Crompton \& Love [10] have perceived quality in the tourism contextual as quality of performance and quality of experience. Quality of performance (quality) is the attribute of a service which is fully controlled by provider, while quality of experience (satisfaction) is the visitors' psychological effect that turned out from accomplishment of expectations that influenced by quality attributes and external factors. In addition, quality can affect satisfaction and in turn produce an impact on evaluation and improvement that will grow number of visitors and/or revenues [18]-[22].

Accordingly, this research justify that event quality must be take into main consideration for it directly controlled by event provider. On the contrary, provider cannot control psychological factors (moods, emotions, feelings) and external factors (weather, climate). Therefore, provider can put their attention to deliver the highest quality of performance that they can control. For example, Baker and Crompton [20] were determined 4 dimensions and 18 attributes of event quality: generic features, specific entertainment features, information sources and comfort amenities. They research indicated that quality has impact on satisfaction and satisfaction will lead to behavior intention of 
visitors. Moreover, Crompton [15] was assessed six factors of event quality. Although this research had inconclusive results, but the assessment of those factors offered intuitive information and helpful direction for further research. Further, Cole and Chancellor [23] were defined 3 factors (entertainment, amenities and programs) which consist of 15 criteria, where the result showed that entertainment had more effects than the remaining factors. Consequently, it suggested that provider should constantly examine and improve the event quality based on various factors related. The previous event studies have emphasized an evaluation system that interprets the assessment of dimensions and criteria in this research.

\section{Methodology}

The DEMATEL method which generally used to solve the complicated and intertwined problems in MCDM is proposed in this research to confirm the effect of each factor and influential relationships between them.

\section{A. Data Collection}

A list of factors that related to event quality was identified as listed in Table I. Those factors include 4 dimensions and 21 criteria. The questionnaire was designed with question responses ranged from 0 to 4 that describe influential degree among dimensions and criteria. In this research, the questionnaire was filled by three groups comprised of 26 experts: nine scholars in tourism study, another eight from government officials in various departments and the last nine are various event providers. The ideas on the assessment criteria were compiled through personal interview and completed surveys which focused on event quality. Surveys were obtained on June 2011 and each expert took about 90 minutes to be interviewed and filled the questionnaire.

\section{B. Building a Network Relationship Using the DEMATEL}

In this research, DEMATEL method is used to analyze the interdependence of influential relationships among factors into an intelligible structural model of system and build an influential network relationship map (INRM). This method uses matrix calculations to confirm all of the direct and indirect influential relationships, as well as the impact strength. Then, a visual structural matrix and influence diagram is displayed to show the influential relationship and influential degree among the dimensions and criteria in a complex system [24]-[27]. For the result, this assists the decision making process with a visual representation illustrated by INRM that can be used to discover the main of the problem and find out which factors affect each other or themselves.

The procedures of DEMATEL method can be summarized in the following steps:

Step 1: Find the average matrix.

Suppose $Z$ experts and $n$ criteria as consideration in this research. For the $k$ th expert, the pairwise comparisons between criterion $i$ affects criterion $j$ can be denoted by $x_{i j}^{k}$.

The evaluation score are given ranging from $0,1,2,3$ and 4 , representing 'no influence (0), 'low influence (1)', 'medium influence (2)', 'high influence (3)' and 'very high influence (4)', respectively. The scores by each experts will give the answer of matrix $X^{k}=\left[x_{i j}^{k}\right]$, with $1 \leq k \leq Z$. Then we can compute the $n \times n$ average matrix $A$ for all expert opinions by averaging the $Z$ experts' score as follows:

$$
a_{i j}=\frac{1}{z} \sum_{k=1}^{z} x_{i j}^{k}
$$

The average matrix $A=\left[a_{i j}\right]_{n x n}$ is also called the initial direct-relation matrix $A$, shows the initial direct effects that a factor exerts on and receives from other factors.

Step 2: Calculate the normalized initial direct-relation matrix.

The initial direct influence matrix $D$ (i.e., $D=\left[d_{i j}\right]_{n x n}$ ) can be derived by normalizing the average matrix $A$ in the following way.

$$
\begin{gathered}
D=A / u \\
u=\max \left(\max _{1 \leq i \leq n} \sum_{j=1}^{n} a_{i j}, \max _{1 \leq j \leq n} \sum_{i=1}^{n} a_{i j}\right)
\end{gathered}
$$

Step 3: Compute the total relation matrix

A continuous decrease of the indirect effects of problems along the power of matrix $D$ and the use of Markov chain skill can gain the total relation matrix. The total relation matrix $T$ is an $n x n$ matrix and is defined as follows:

$$
T=D+D^{2}+\ldots+D^{m}=D(I-D)^{-1}
$$

Then, the vector $\boldsymbol{r}$ and $\boldsymbol{c}$ can be defined sum of row and sum of column from the matrix $T$ by equation (5) and (6) as following:

$$
\begin{gathered}
r=\left[r_{i}\right]_{n x 1}=\left(\sum_{j=1}^{n} t_{i j}\right)_{n x 1} \\
c=\left[c_{j}\right]_{1 x n}^{\prime}=\left(\sum_{i=1}^{n} t_{i j}\right)_{1 x n}^{\prime}
\end{gathered}
$$

\begin{tabular}{|c|c|}
\hline & QUALITY \\
\hline Dimensions & Criteria \\
\hline \multirow[t]{6}{*}{ Entertainment $\left(\boldsymbol{D}_{1}\right)$} & Ticket $\left(C_{11}\right)$ \\
\hline & Program performance $\left(C_{12}\right)$ \\
\hline & Varied program $\left(C_{13}\right)$ \\
\hline & Program arrangement $\left(C_{14}\right)$ \\
\hline & Food \& Beverage $\left(C_{15}\right)$ \\
\hline & Souvenir $\left(C_{16}\right)$ \\
\hline \multirow[t]{5}{*}{ Transportation $\left(\boldsymbol{D}_{2}\right)$} & Public transport $\left(C_{21}\right)$ \\
\hline & Way to location $\left(C_{22}\right)$ \\
\hline & Parking location $\left(C_{23}\right)$ \\
\hline & Distance to location $\left(C_{24}\right)$ \\
\hline & Venue $\left(C_{25}\right)$ \\
\hline \multirow[t]{6}{*}{ Information $\left(\boldsymbol{D}_{3}\right)$} & Pre-information $\left(C_{31}\right)$ \\
\hline & Pamphlet $\left(C_{32}\right)$ \\
\hline & Guide $\left(C_{33}\right)$ \\
\hline & Varied information $\left(C_{34}\right)$ \\
\hline & Staff performance $\left(C_{35}\right)$ \\
\hline & Number of Staff $\left(C_{36}\right)$ \\
\hline \multirow[t]{4}{*}{ Environment $\left(\boldsymbol{D}_{4}\right)$} & Cleanliness $\left(C_{41}\right)$ \\
\hline & Restroom $\left(C_{42}\right)$ \\
\hline & Entrance and exit $\left(C_{43}\right)$ \\
\hline & Rest area $\left(C_{44}\right)$ \\
\hline
\end{tabular}

where superscript " " " denotes transpose.

TABLE I: THE DIMENSIONS AND CRITERIA ASSOCIATED WITH EVENT 
The $r_{\mathrm{i}}$ denotes the sum of $i$ th row in total relation matrix $T$. Then it shows the total effects, both direct and indirect, given by factor $i$ to the other criteria. The $c_{\mathrm{j}}$ means the sum of the $j$ th column in matrix $T$. The $c_{\mathrm{j}}$ shows the total effects received by criterion $j$ from the other criteria. When $j=i$, the sum of $\left(r_{i}+c_{i}\right)$ indicates an index representing the total effects both given and received by criterion $i$. In addition, the $\left(r_{i}-c_{i}\right)$ means the net effect that criterion $i$ contributes to the system. When the index of $\left(r_{i}-c_{i}\right)$ is positive, the criterion $i$ is net causer. In other words, when the index $\left(r_{i}-c_{i}\right)$ is negative, the criterion $i$ is net receiver.

\section{ANALYSIS AND RESULTS}

Every event has their uniqueness and appeal to create interest and attract visitors' attention which always demanding and expecting for more unique and engaging experiences. The use of case study and methodology will demonstrate how provider can enhance their effectiveness and efficiency in producing improvement plans that will meet their goal.

\section{A. Problems Description}

The Taipei International Expo had total attendance almost 9 million visitors and created economic benefits about NT\$ 18.8 billion. This research took this expo as an empirical case study which designed to intend the most favorable improvement plan for event provider. Event quality is determined by many factors related. The purpose of this research is to help provider in decision making process in quality improvement. Provider can find out the influential relationships between dimensions and criteria associated with event quality by using DEMATEL method, and in turn design the improvement strategy based on priority sequences among those dimensions and criteria.

\section{B. Construct INRM Using DEMATEL}

Based on the questionnaires that filled by 26 experts, we define the initial direct-relation matrix and further normalized as the matrix $\boldsymbol{D}$ (as shown in Table II) using DEMATEL, then calculate the total relation matrix $\boldsymbol{T}$ of the criteria (Table III). The consistency test with a high consistency ratio of $95.26 \%$ indicates that the result is significantly dependable. According to the values of $\left(r_{i}+c_{i}\right)$ and $\left(r_{i}-c_{i}\right)$, the results for the dimensions and criteria are shown in Table IV. This result allows us to construct INRM as illustrated in Figure 1. When $\left(r_{i}+c_{i}\right)$ is high and $\left(r_{i}-c_{i}\right)$ is positive, it means that the criterion has most influence and be a primary key to be concerned about. In contrast, when $\left(r_{i}+c_{i}\right)$ is high and $\left(r_{i}-c_{i}\right)$ is negative, it means that the criterion is highly significant to be influenced by other criteria.

TABLE II: NORMALIZED MATRIX D

\begin{tabular}{|c|c|c|c|c|c|c|c|c|c|c|c|c|c|c|c|c|c|c|c|c|c|}
\hline & & & & & & & 1 & 22 & $C_{23}$ & $C_{24}$ & $C_{25}$ & 31 & 32 & 33 & 34 & 35 & 36 & 41 & $C_{42}$ & $C_{43}$ & 44 \\
\hline & & & & & & & & & & & & & & & & & & & & & \\
\hline & & & & & & & & & & & & & & & & & & & & & \\
\hline & & & & & & & & & & & & & & & & & & & & & \\
\hline & & & & & 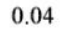 & & & & & & & & & & & & & & & & \\
\hline & & & & & 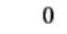 & & & & & & & & & & & & & & & & \\
\hline & & & & & 02 & & & & & & & & & & & & & & & & \\
\hline & & & & & 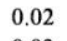 & 02 & 0 & & & & & & & & & & & & & & \\
\hline & & & & & & & & 0 & & & & & & & & & & & & & \\
\hline & & & & & & 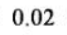 & 0 & 0.06 & 0 & & & & & & & & & & & & 0 \\
\hline & & & & & & & & & . & & & & & & & & & & & & \\
\hline & & & & & & & 5 & & 0 & & 0 & & & & & & & & & & \\
\hline & & & & & & & & & & & & 0 & & & & & & & & & \\
\hline & & & & & & & & & & & & & 0 & & & & & & & & \\
\hline & & & & & & & & & & & & & & 0 & & & & & & & 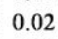 \\
\hline & & & & & & & & & & & & & & & & & & & & & \\
\hline & & & & & & & & & & & & & & & & 0 & 6 & & & & .0. \\
\hline & & & & & & & & & & & & & 0 & & & & 0 & 06 & & & \\
\hline & & & & & & & & & & & & & & & & & & & & & \\
\hline & & & & & & & & & & & & & & & & & & & & & .0 \\
\hline & & & & & .02 & 02 & 0.03 & 0.04 & 0.04 & 0.05 & 0.04 & 0.03 & 0.02 & 0.02 & 0.02 & 0.02 & 0.03 & 0.06 & 0.04 & & .03 \\
\hline & & .02 & 02 & 04 & 03 & 02 & 02 & 0.02 & 0.02 & 0.02 & 0.03 & 0.04 & 0.02 & 0.02 & 0.03 & 0.02 & 0.02 & 0.06 & 0.04 & 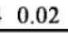 & \\
\hline
\end{tabular}
Note: $\frac{1}{n^{2}} \sum_{i=1}^{n} \sum_{j=1}^{n} \frac{\left|t_{i j}^{p}-t_{i j}^{p-1}\right|}{t_{i j}^{p}} x 100 \%=4.74 \%<5 \%$, consistency ratio $95.26 \%$ denote the average influence of $\mathrm{i}$ criterion to $\mathrm{j}$.

The results displayed that entertainment $\left(D_{1}\right)$ has the highest influence level that impact remaining dimensions directly. Additionally, environment $\left(D_{4}\right)$ has the lowest influential degree and is the most vulnerable to impact other dimensions. As presented in Table III, the prioritization of influential degree can be sequenced as: $D_{1} D_{2} D_{3} D_{4}$. Regarding the aim of improvement, the first priority to be improved should be entertainment $\left(D_{1}\right)$, for it can bring out influential impact to other dimensions: transportation $\left(D_{2}\right)$, information $\left(D_{3}\right)$ and environment $\left(D_{4}\right)$. Hence, provider should manage their concern to this standpoint. In addition, experts in event studies clarify that entertainment has most influential impact on an event and improvement of this dimension will bring out an influence on remaining dimensions as well. The influential relationship also can be seen within each dimension and criteria. As an example, within the dimensions of entertainment $\left(D_{1}\right)$, it can be identified that varied program $\left(C_{13}\right)$ affected the remaining criteria. Conversely, souvenir $\left(C_{16}\right)$ is accepted the most influence from other criteria. This result supports previous research which revealed that the event program significantly drove out satisfaction and influenced visitors to attend an event [7], [28]. Taken as a whole, the particular order of general improvement priority for entertainment $\left(D_{1}\right)$ is: 
$\left(C_{13}\right)_{-}\left(C_{14}\right)_{-}\left(C_{12}\right)_{-}\left(C_{11}\right)_{-}\left(C_{15}\right)_{-}\left(C_{16}\right)$. Similar influential relationships also can be defined for the remaining criteria within other dimensions, as illustrated in detail in Fig. 1. This method is a helpful tool for decision-making process in identifying priority for improvement strategy of event quality.

TABLE III: TOTAL RELATION MATRIX T

\begin{tabular}{|c|c|c|c|c|c|c|c|c|c|c|c|c|c|c|c|c|c|c|c|c|c|}
\hline & & & & & & & & & 3 & & 5 & 1 & 32 & $C_{33}$ & 34 & 35 & $C_{36}$ & $C_{41}$ & $C_{42}$ & 43 & 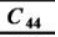 \\
\hline & & & & & & & & & & & & & & & & & 020 & & & & \\
\hline & & & & & & & & & & & & & & & & & & & & & \\
\hline & & & & & & & & & & & & & & & & & & & & & \\
\hline & & & & & & & & & & & & & & & & & & & & & \\
\hline & & & & & & & & & & & & & & & & & & & & & \\
\hline & & & & & & & & & & & & & & & & & & & & & \\
\hline & & & & & & & & & & & & & & & & & & & & & \\
\hline & & & & & & & & & & & & & & & & & & & & & \\
\hline & & & & & & & & & & & & & & & & & & & & & \\
\hline & & & & & & & & & & & & & & & & & & & & & \\
\hline & & & & & & & & & & & & & & & & & & & & & \\
\hline & & & & & & & & & & & & & & & & & & & & & \\
\hline & & & & & & & & & & & & & & & & & & & & & \\
\hline & & & & & & & & & & & & & & & & & & & & & \\
\hline & & & & & & & & & & & & & & & & & & & & & 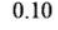 \\
\hline & & & & & & & & & & & & & & & & & & & & & 0 \\
\hline & & & & & & & & & & & & & & & & & & & & & 0 \\
\hline & & & & & & & & & & & & & & & & & & & & & \\
\hline & & & & & & 0. & & & & & & & & & & & & & & & \\
\hline & & & & & & 0.0 & & & & & & & & & & & & & & & \\
\hline & & & & & & & & & & & & & & & & & & & & & \\
\hline
\end{tabular}

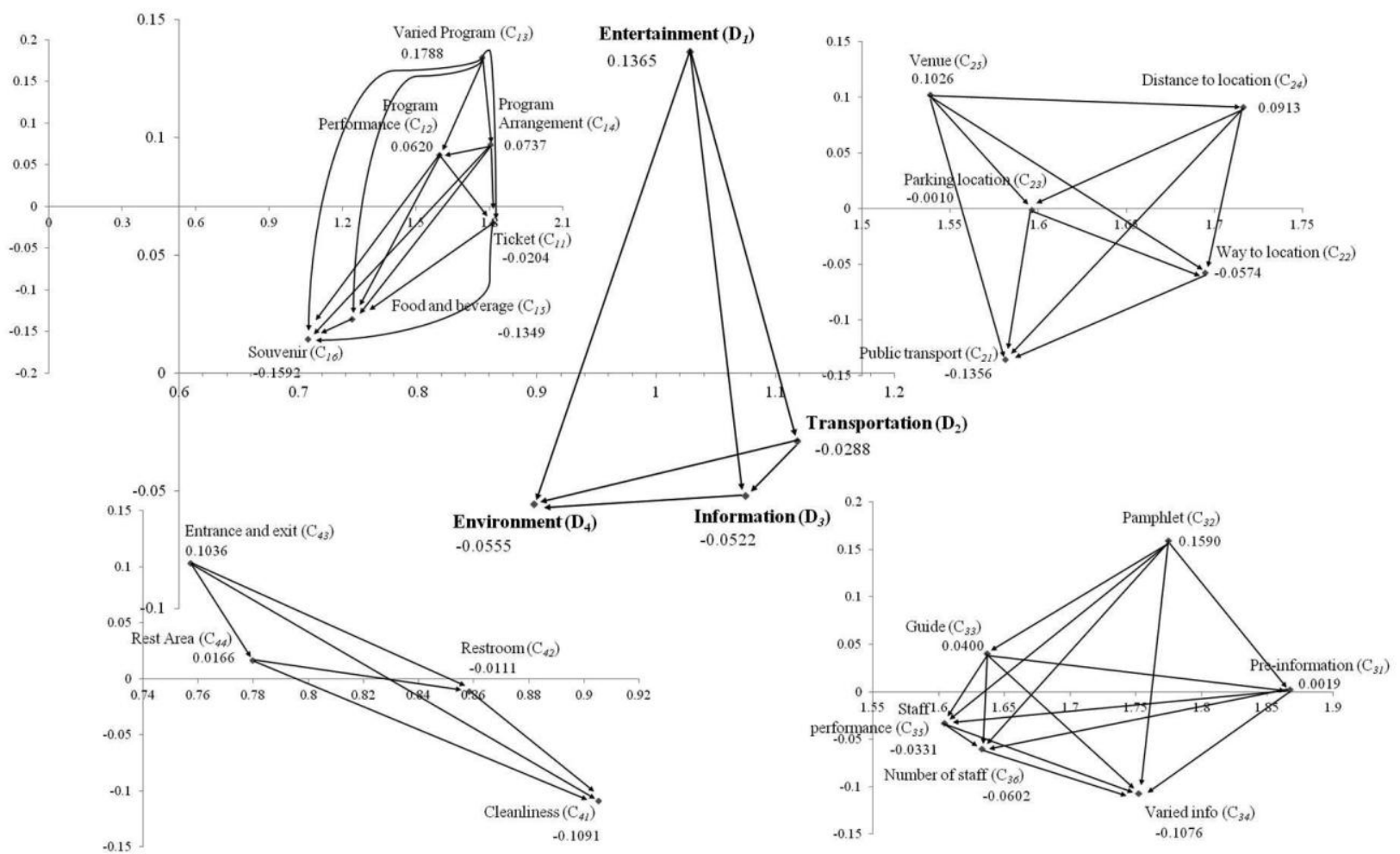

Fig. 1. Influential Network Relationships Map

TABLE IV: RESULTS OF DIMENSIONS / CRITERIA ANALYSIS

\begin{tabular}{lcccc}
\hline Dimensions / Criteria & $\mathrm{r}$ & $\mathrm{c}$ & $\mathrm{r}+\mathrm{c}$ & $\mathrm{r}-\mathrm{c}$ \\
\hline Entertainment $\left(\boldsymbol{D}_{\mathbf{1}}\right)$ & $\mathbf{0 . 5 8 2 4}$ & $\mathbf{0 . 4 4 5 9}$ & $\mathbf{1 . 0 2 8 4}$ & $\mathbf{0 . 1 3 6 5}$ \\
Ticket $\left(C_{11}\right)$ & 0.8964 & 0.9167 & 1.8131 & -0.0204 \\
Program performance $\left(C_{12}\right)$ & 0.8285 & 0.7665 & 1.5949 & 0.0620 \\
Varied program $\left(C_{13}\right)$ & 0.9740 & 0.7951 & 1.7691 & 0.1788 \\
Program arrangement $\left(C_{14}\right)$ & 0.9389 & 0.8652 & 1.8040 & 0.0737 \\
Food and beverages $\left(C_{15}\right)$ & 0.5514 & 0.6863 & 1.2377 & -0.1349 \\
Souvenir $\left(C_{16}\right)$ & 0.4501 & 0.6093 & 1.0593 & -0.1592 \\
Transportation $\left(\boldsymbol{D}_{\mathbf{2}}\right)$ & $\mathbf{0 . 5 4 4 8}$ & $\mathbf{0 . 5 7 3 6}$ & $\mathbf{1 . 1 1 8 5}$ & $\mathbf{- 0 . 0 2 8 8}$ \\
Public transport $\left(C_{21}\right)$ & 0.7228 & 0.8583 & 1.5811 & -0.1356
\end{tabular}

Way to location $\left(C_{22}\right)$

Parking location $\left(C_{23}\right)$

Distance to location $\left(C_{24}\right)$

Venue $\left(C_{25}\right)$

Information $\left(D_{3}\right)$

Pre-information $\left(C_{31}\right)$

Pamphlet and signage $\left(C_{32}\right)$

Guide $\left(C_{33}\right)$

Varied information $\left(C_{34}\right)$

Staff performance $\left(C_{35}\right)$

Number of Staff $\left(C_{36}\right)$
0.8187

0.7976

0.9039

0.8207

0.5113

0.9346

0.9669

0.8384

0.8223

0.7856

0.7864
0.8760

1.6947

$0.7986 \quad 1.5962$

$0.8126 \quad 1.7165$

$0.7181 \quad 1.5388$

0.56351 .0748

$0.9327 \quad 1.8673$

$0.8080 \quad 1.7749$

$0.7984 \quad 1.6368$

$0.9298 \quad 1.7521$

$0.8187 \quad 1.6043$

$0.8466 \quad 1.6330$
$-0.0574$

$-0.0010$

0.0913

0.1026

$\mathbf{- 0 . 0 5 2 2}$

0.0019

0.1590

0.0400

$-0.1076$

$-0.0331$

$-0.0602$ 


\begin{tabular}{lllll} 
Environment $\left(\boldsymbol{D}_{4}\right)$ & $\mathbf{0 . 4 2 1 2}$ & $\mathbf{0 . 4 7 6 7}$ & $\mathbf{0 . 8 9 7 8}$ & $\mathbf{- 0 . 0 5 5 5}$ \\
Cleanliness $\left(C_{41}\right)$ & 0.3980 & 0.5072 & 0.9052 & -0.1091 \\
Restroom $\left(C_{42}\right)$ & 0.4236 & 0.4347 & 0.8583 & -0.0111 \\
Entrance and exit $\left(C_{43}\right)$ & 0.4304 & 0.3268 & 0.7572 & 0.1036 \\
Rest area $\left(C_{44}\right)$ & 0.3981 & 0.3815 & 0.7796 & 0.0166 \\
\hline
\end{tabular}

\section{CONCLUSION}

At present, event providers constantly put efforts in providing satisfactory environment for visitors. When provider can deliver more satisfying product and service quality, then they will be capable taking lead among competitive circumstances in event industries. However, different types or characteristics of events including the factors of event quality may or may not same, but those factors are various and complicated. So, the methodologies should be taken as consideration in order to achieve the goal. Getz [29] noted that the approaches from various research methodologies are found to be useful in establishing event structure. This research applied DEMATEL method to construct an influence relationships system, which can assist decision makers to directly evaluate and improve factors of events according to their influential degree.

However, the results of this research may not be generalized to other types of events because probably there is sampling error in one sampling event. Future research may take other objects, industry fields or methodologies for gaining knowledge, obtaining useful insights and advancing concepts in event studies. The application of DEMATEL can support provider to discover the prioritization of event quality improvement and direct their attention to create a better event quality.

\section{REFERENCES}

[1] D. Getz, Festivals, Special Events, in Khan, M. A., Olsen, M. D. and T. Var, (Eds), Encyclopedia of Hospitality and Tourism, Van Nostrand Reinhold, New York, NY, 1993, pp. 789-810.

[2] J. L. Crompton and S. L. McKay, "Measuring the economic impacts of festivals and events: Some myths, misapplications and ethical dilemmas," Festival Management \& Event Tourism, vol. 2, no.1, pp 33-43, 1994.

[3] D. Getz, Event Management and Event Tourism, New York: Cognizant Communication, 1997.

[4] D. Felsenstein and A. Fleischer, "Local Festivals and Tourism Promotion: The Role of Public Assistance and Visitor Expenditure," Journal of Travel Research, vol. 41, no.4, pp. 385-392, 2003.

[5] C. Lee, Y. Lee, and B. Wicks, "Segmentation of festival motivation by nationality and satisfaction," Tourism Management, vol. 25, no. 1, pp 61-70, 2004.

[6] B. McKercher, W. Mei, and T. Tse, "Are short duration festivals tourist attractions?" Journal of Sustainable Tourism, vol. 14, no. 1, pp. 55-66, 2006.

[7] Y. Lee, C. Lee, S. Lee, and B. Babin, "Festivalscapes and patrons' emotions, satisfaction and loyalty," Journal of Business Research, vol 61 , no. 1, pp. 56-64, 2008.

[8] Y. W. Chen, and G. H. Tzeng, "Using fuzzy integral for evaluating subjectively perceived travel costs in a traffic assignment model", European Journal of Operational Research, vol. 130, pp. 653-664, 2001.

[9] G. H. Tzeng and J. J. Huang, Multiple Attribute Decision Making: Methods and application, New York: CRC Press, Taylor \& Francis publishing group, 2011.

[10] J. L. Crompton and L. Love, "The Predictive Validity of Alternative Approaches to Evaluating Quality of a Festival," Journal of Travel Research, vol. 34, no. 1, pp. 11-24, 1995.

[11] D. Getz, M. O'Neill, and J. Carlsen, "Service Quality Evaluation at Events through Service Mapping," Journal of Travel Research, vol. 39, pp. 380-390, 2001.
[12] D. R. Howard, and J. L. Crompton, Financing, Managing, and Marketing Recreation and Park Resources, Wm. C. Brown Company, Dubuque, Iowa, 1980.

[13] F. Herzberg, B. Mausner, and B. B. Snyderman, The motivation to work, New. York: Wiley, 1959.

[14] M. Bitner, "Evaluating Service Encounters: The Effects of Physical Surroundings and Employee Responses," Journal of Marketing, vol. 54, April, pp. 69-82, 1990.

[15] J. L. Crompton, "Adapting Herzberg: A Conceptualization of the Effects of Hygiene and Motivator Attributes on Perceptions of Event Quality," Journal of Travel Research, vol. 41, pp. 305-310, 2003.

[16] A. Mehrabian and J. Russell, An Approach to Environmental Psychology, Cambridge, Mass.: MIT Press, 1974.

[17] P. J. Brown, "Quality in Recreation Experience, in Outdoor Recreation Benchmark 1988: Proceedings of the National Recreation Forum, A. H. Watson (ed.), Tampa, Florida, USDA Forest Service, General Technical Report SE-52, 1988.

[18] J. L. Crompton and S. L. McKay, "Motives of visitors attending festival events," Annals of Tourism Research, vol. 6, no. 4, pp. 425-39, 1997.

[19] R. D. Childress and J. L. Crompton, "A comparison of alternative direct and discrepancy approaches to measuring quality of performance at a festival," Journal of Tourism Research, vol. 36, no. 2, pp. 43-57, 1997.

[20] D. A. Baker and J. L. Crompton, "Quality, satisfaction and behavioral intentions," Annals of Tourism Research, vol. 27, no. 3, pp. 785-804, 2000.

[21] S. T. Cole and J. L. Crompton, "A conceptualization of the relationships between service quality and visitor satisfaction, and their links to destination selection," Leisure Studies, vol. 22, pp. 65-80, 2003.

[22] Y. S. Yoon, J. S. Lee, and C. K. Lee, "Measuring festival quality and value affecting visitors' satisfaction and loyalty using a structural approach," International Journal of Hospitality Management, vol. 29 pp. 335-342, 2010.

[23] S. T. Cole and H. C. Chancellor, "Examining the festival attributes that impact visitor experience, satisfaction and re-visit intention," Journal of Vacation Marketing, vol. 15, pp. 323-333, 2009.

[24] V. Y. C. Chen, H. P. Lien, C. H. Liu, J. J. H. Liou, G. H. Tzeng, and L. S. Lang, "Fuzzy MCDM approach for selecting the best environment-watershed plan," Applied soft computing, vol. 11, pp. 265-275, 2011.

[25] C. H. Huang, G. H. Tzeng, and W. R. Ho, "System on chip design service e-business value maximization through a novel MCDM framework," Expert Systems with Applications, vol. 38, pp. 7947-7962, 2011.

[26] C. Y. Huang, J. Z. Shyu, and G. H. Tzeng, "Reconfiguring the innovation policyportfolios for Taiwan's SIP mall industry," Technovation, vol. 27, pp. 744-765, 2007.

[27] J. L. Yang and G. H. Tzeng, "An integrated MCDM technique combined with DEMATEL for a novel cluster-weighted with ANP method," Expert Systems with Applications, vol. 38, pp. 1417-1424, 2011.

[28] F. Saleh and C. Ryan, "Jazz And Knitwear: Factors That Attract Tourists To Festivals," Tourism Management, vol. 14, no. 4, pp. 289-297, 1993.

[29] D. Getz, "Event tourism: Definition, evolution, and research," Tourism Management, vol. 29, pp. 403-428, 2008.

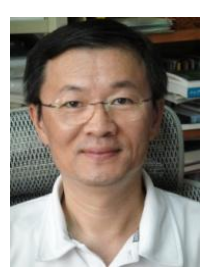

Wen-Tsann Yang was born in Taipei, Taiwan on December $9^{\text {th }}, 1955$. He finished his M.S degree of Forestry from University of Montana, Missoula, Montana, USA in 1984, and earned Ph. D degree of Geography from Southern Illinois University, Carbondale, Illinois, USA in 1992. After his study in USA, he went back to Taiwan to serve as an associate professor in Department of Land management at Feng Chia University, Taichung, Taiwan. He has been teaching some courses such as: Environment and Ecology, Commercial Recreation Management in undergraduate program, and Recreation Theories, Graduate Seminar and Conflict Management in graduate program for more than 20 years. Besides teaching, he has continued conducting research financially supported by National Science Council in Taiwan. The major study topics including: visitors' littering behaviors in recreation areas, ecotourism planning and management in aboriginal tribal areas, sexual leisure in metropolitan areas, and so on.

He was a co-author of a book with other 19 authors, titled as "Leisure and Recreation: Theories and Practices", edited by Dr. Ou with $1^{\text {st }}$ edition in 2007 and $2^{\text {nd }}$ edition in 2011, respectively published by Chien-Tsen Cultural Business Co. New Taipei City, Taiwan. Various articles based on his studies 
were published both in different journals and conference proceedings. The future study in which he is interested would be topics relevant to emotional labor in service business, such as managers of recreation areas, real estate agents and/or tour guides.

Dr. Yang has been serving as executive councilor in the board of Outdoor Recreation Association in Taiwan, Member of the Evaluation Team in Taiwan Tourism Bureau, Paper Reviewer of Journal of Outdoor Recreation Studies in Taiwan, and so on for many years. In addition, he won Excellent Teacher Award from Feng Chia University, Taichung Taiwan in 1997, Contribution Award 2011 and 2012 from Overseas Mandarin Council in Taiwan.

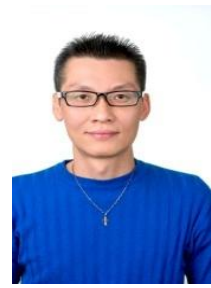

Wen-Hua Liu was born in Taipei, Taiwan on April $25^{\text {th }}$, 1969. He has a master's degree of tourism management from Chinese Culture University, Taipei, Taiwan in 2008. He is currently a third year PhD student at Feng Chia University, Taichung, Taiwan in Civil and Hydraulic Engineering with resource management as major field of study.

He started his own business in human resources and travel services industries. Besides, he has been teaching Tourism English at Taipei College of Maritime Technology for the past five years, and has been actively teaching Travel and Industry Management at Feng Chia University, Taichung, Taiwan since 2012.

$\mathrm{He}$ has published several papers based on the $\mathrm{Ph}$. D research which focus on fields of tourism and recreation, as well as other fields related to resource management. His research interests are including tourism management and MCDM (Multiple Criteria Decision Making) methods.

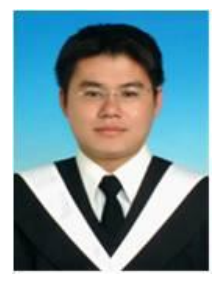

Hsin-Hsien Liu was born in Taichung, Taiwan on October $8^{\text {th }}$, 1981. He was graduated from Feng Chia University $\mathrm{Ph}$. D. program in Civil and Hydraulic Engineering, Taichung, Taiwan in 2012, with the railway industry reform as major field of study.

$\mathrm{He}$ had worked as research assistant in Research Center of Traffic Accident Appraisal (RCTAA) and Advanced Traffic Management Center in Feng Chia University, Taichung Taiwan during 2006-2012. He also has been teaching Transportation data analysis and Transportation decision making analysis during 2011-2012 at Department of Transportation Technology and Management, Feng-Chia University, Taichung, Taiwan. Currently, he has been serving in the army to be the Substitute Military Service since December 2012

He has published several papers which about transportation safety and railway operation used data mining and MCDM methods. His research interests contain railway industry operation and reform, traffic accident safety and analysis, multiple criteria decision making and data mining.

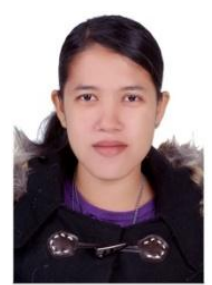

Lanasari was born in Jakarta, Indonesia on March $13^{\text {th }}$, 1985. She was graduated from SMUK Kalam Kudus Senior High School, Jakarta, Indonesia, in 2002, major in science. She was studied abroad at Feng Chia University, Taichung, Taiwan in 2012, with Tourism and Hospitality Management as major field of study.

She had worked as Finance and Accounting Staff at a company in Jakarta, Indonesia for five years. She also has been teaching since 2008 at Suci Hati School, Jakarta, Indonesia, responsible for educating junior high school students in several subjects (Mathematic, Science and Chinese language).

She is interested in social sciences, statistic study and research methodologies, such as MCDM (Multiple Criteria Decision Making) methods. 